\title{
The impact of a governmental policy prohibiting wearing of wristwatches on the measurement of pulse and respiratory rate
}

This article was published in the following Dove Press journal:

Clinical Audit

3I August 2010

Number of times this article has been viewed

\section{David Spitzer}

Barts and the London School of Medicine and Dentistry, Queen Mary University of London, London, UK
Correspondence: David Spitzer 4 Whiteways, Hillview Gardens, London NW4 2JG, UK

Tel +44 0 789l 727576

Email davidspitzerl@gmail.com
Background: It is recommended that pulse and respiratory rates are measured accurately rather than estimated. The UK's 'bare below the elbow' policy prohibiting hospital doctors from wearing wristwatches conflicts with this guidance.

Objective: To assess (a) whether pulse/respiratory rates are measured accurately or estimated, (b) adherence to the 'bare below the elbow' policy with regard to the wearing of wristwatches, and (c) if the policy has affected whether pulse/respiratory rates are measured or estimated.

Method: A questionnaire was distributed to 52 doctors (with a wide range of experience) working in medical and surgical wards, accident and emergency and the intensive care unit at the Homerton University Hospital, London, UK.

Results: Findings indicated that (a) there is wide variation of practice over whether pulse/ respiratory rates are measured accurately or estimated, (b) doctors generally adhere to instructions not to wear wristwatches, and (c) a majority of doctors indicate that the 'bare below the elbow' policy has affected their behavior with regard to measurement of pulse and respiratory rate.

Conclusions: If the importance of accurate measurement of pulse/respiratory rate is accepted, these findings suggest that doctors be provided with watches which they can attach to other parts of their clothing or neck fobs. Although not ideal, this solution provides a way of resolving the conflict between the 'bare below the elbow' policy and accurate measurement of pulse and respiratory rate.

Keywords: pulse, respiratory rate, measurement, governmental policy, bare below the elbow, dress code, wristwatch, clinical audit

\section{Introduction}

\section{Standards for measurement of pulse and respiratory rate}

The key physiological indicators of pulse and respiratory rate are fundamental to clinical assessment of patients, and are used in early warning scores. Many textbooks of medicine and clinical skills lay down that pulse and respiratory rate should be counted for a short period (fifteen or twenty seconds) and then multiplied to give the rate as a 'per minute' measurement; ${ }^{1-4}$ this is also the way that medical schools teach (and examine) these clinical skills. One of the aims of this audit was to discover whether this standard is adhered to by doctors in their daily practice.

\section{'Bare below the elbow' policy}

The 'bare below the elbow' policy was introduced in November 2007 by the Secretary of State for Health, ${ }^{5}$ and Homerton University Hospital introduced this policy shortly thereafter, including a prohibition on the wearing of wristwatches (see Figure 1). ${ }^{6}$ 


\section{Homerton is bare below the elbow}

On 1 January 2008 Homerton became a 'bare below the elbow' zone in the latest initiative to combat the spread of infection.

From now on all clinical staff, when caring for patients, should not wear anything below the elbow including white coats and long sleeve shirts. Bracelets, watches and other wrist jewellery are also not allowed, along with rings (apart from plain wedding bands). In addition, clinical staff have stopped wearing ties and bowties.

Figure I Bare below the elbow policy, as set out by the Homerton Hospital patient information website.

The policy has been the target of criticism on several fronts, including lack of evidence for the policy, the suggestion that it was politically motivated, the difficulties it poses to some religious groups and inconsistencies such as allowing plain wedding bands. ${ }^{7-8}$ This audit does not aim to investigate these areas. This audit concentrates on another consequence of the policy: that it restricts clinicians' access to wristwatches when measuring vital signs such pulse and respiratory rates.

\section{Conflict between these two guidelines}

Thus, the recommendation to time the pulse/respiratory rate against a watch comes into conflict with the "bare below the elbow' policy. The two are not necessarily incompatible; however resolving the conflict requires a watch to be acquired from another source. If this is not done, one recommendation will have to be sacrificed.

\section{Purpose}

The aims of this audit were to assess how often people estimate pulse and respiratory rate rather than the standard of measuring against a watch, and whether the 'bare below the elbow' policy has had an effect on this behavior. For the sake of clarity, these aims have been divided into three distinct questions:

1. To audit whether doctors measure pulse and respiratory rates exactly, or estimate.

2. To audit levels of adherence to the bare below the elbow policy, specifically with regard to the wearing of wristwatches.

3. To investigate whether the 'bare below the elbow' policy has had an impact on how pulse/respiratory rate is measured.

\section{Method}

Data were collected by asking doctors working at the Homerton University Hospital to complete a questionnaire. Doctors ranged from newly qualified to consultants with many years' clinical experience. The questionnaire was only offered to doctors who worked in medical and surgical wards, accident and emergency and intensive care unit, and who cared for inpatients. Doctors from other specialties, and those only seeing outpatients, were excluded.

The first aim, to audit adherence to the 'bare below the elbow' policy, was carried out by asking whether the respondent wore a wristwatch (on the wrist) in hospital.

The second aim, to audit accurate measurement of the pulse/respiratory rate, was achieved by asking respondents how often they estimated rather than measured these signs.

The third aim was to investigate whether the 'bare below the elbow' policy has influenced how pulse and respiratory rate are measured. This was done by asking directly whether respondents felt that the policy had affected the way they take the pulse. Another approach was to ask whether doctors who estimated would measure these rates exactly if they had watches available.

\section{Results \\ Respondents}

Fifty-two doctors completed the questionnaire (a response rate of 100\%). Doctors were grouped into categories. There were approximately equal numbers of each category: 16 newly qualified (Foundation Year 1) (31\%); 20 junior doctors with one to five years' experience (Foundation Year 2 to Specialist Training 3) (38\%); and 16 doctors with more than five years' clinical experience (Specialty Training 4 and above) (31\%).

\section{Accurate measurement or estimation of pulse/respiratory rate}

All respondents answered the question "How often do you estimate the pulse/respiratory rate, rather than using a watch (or other method such as automated monitor) to measure it?" 20 respondents $(38 \%)$ answered "Often or 
always", 18 respondents (35\%) answered "Sometimes", and 14 respondents $(27 \%)$ answered that they never estimated (see Figure 2).

The results were stratified according to the level of experience of the respondent (see Figure 3).

\section{Adherence to the "bare below the elbow' policy}

In answer to the question "Do you wear a wristwatch in hospital?" 46 responded that they did not wear a wristwatch $(88 \%) .6$ responded that they did wear a wristwatch $(12 \%)$.

The reasons for not wearing a wristwatch were assessed asking the question "Why don't you wear a wristwatch?". Of the 46 doctors who previously responded that they did not wear a wristwatch, 44 responded to this question. 39 doctors answered that the reason they did not wear a wristwatch was due to the hospital's 'bare below the elbow' policy (89\%). Four doctors said it was because of personal preference $(9 \%)$, and one answered "Other reason" $(2 \%)$.

\section{Has the 'bare below the elbow' policy affected how pulse/respiratory rate is taken?}

The questions assessing this were only open to those respondents who did not wear wristwatches in hospital.

One question asked was "If you had a watch available on your person, would you use it rather than estimating?". 31 responded that they would use the watch rather than estimating (82\%), whereas 7 said they would still estimate even if they wore a watch $(18 \%)$.

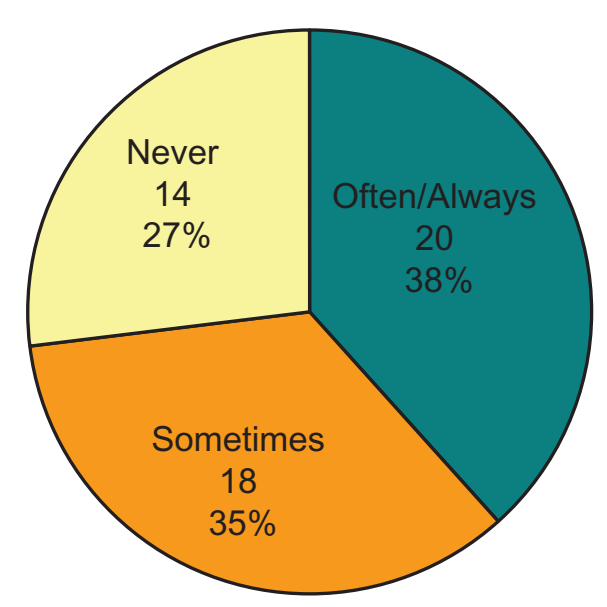

Figure 2 Responses to question "How often do you estimate pulse and respiratory rate?" ( $n=52$. Total responses in each category given as a whole number and then as a percentage).
Another question asked was "Has the bare below the elbow policy affected the way you take pulse/respiratory rate?". 24 responded "Yes" (62\%), and 15 responded "No".

A third question asked was "Do you wear a watch attached to another part of your clothing?". 19 doctors said they wore a watch attached to another part of their clothing (42\%) whereas 26 doctors did not (58\%).

The 19 respondents who did wear watches attached to the other parts of their clothing were then asked how often they estimated pulse and respiratory rate. 5 doctors said they never estimated (26.3\%). 14 said they sometimes, often or always estimated (73.7\%) (5 answered "Often" or "Always" (26.3\%) and 9 answered "Sometimes" (47.4\%).

Of the 14 who sometimes, often or always estimated despite wearing a watch attached to their clothing, 12 said they would use a wristwatch instead of estimating $(85.7 \%)$, whereas 2 said they would still estimate (14.3\%).

\section{Discussion}

\section{Bare below the elbow}

A large majority of doctors do not wear wristwatches $(88 \%)$. Although some of these (11\%) had other reasons, $89 \%$ of those who did not wear a wristwatch said this was because of the 'bare below the elbow' policy. It therefore appears that the policy is generally adhered to.

It is unlikely that the $12 \%$ of doctors who did wear wristwatches were unaware of the policy, which is widely advertised in the hospital. Indeed, several of these respondents commented that they chose to ignore the policy.

\section{Pulse/respiratory rate}

The results show that the proportion of doctors who ever estimate the pulse is $73 \%$, with only $27 \%$ never estimating. This suggests that the recommended way of measuring the pulse is not adhered to by the majority - in fact, 38\% said they often or always estimate.

Looking at whether the doctors' level of experience was a factor, it appeared that more junior doctors tended to measure more and estimate less, whereas more experienced doctors tended to estimate more and measure less.

\section{Would doctors who estimate measure accurately if a watch was available?}

As seen above, the majority of doctors sometimes or always estimate $(73 \%)$ - but $82 \%$ of these said that they would measure using a watch if they had one available. Furthermore, $62 \%$ of respondents felt that the policy had 


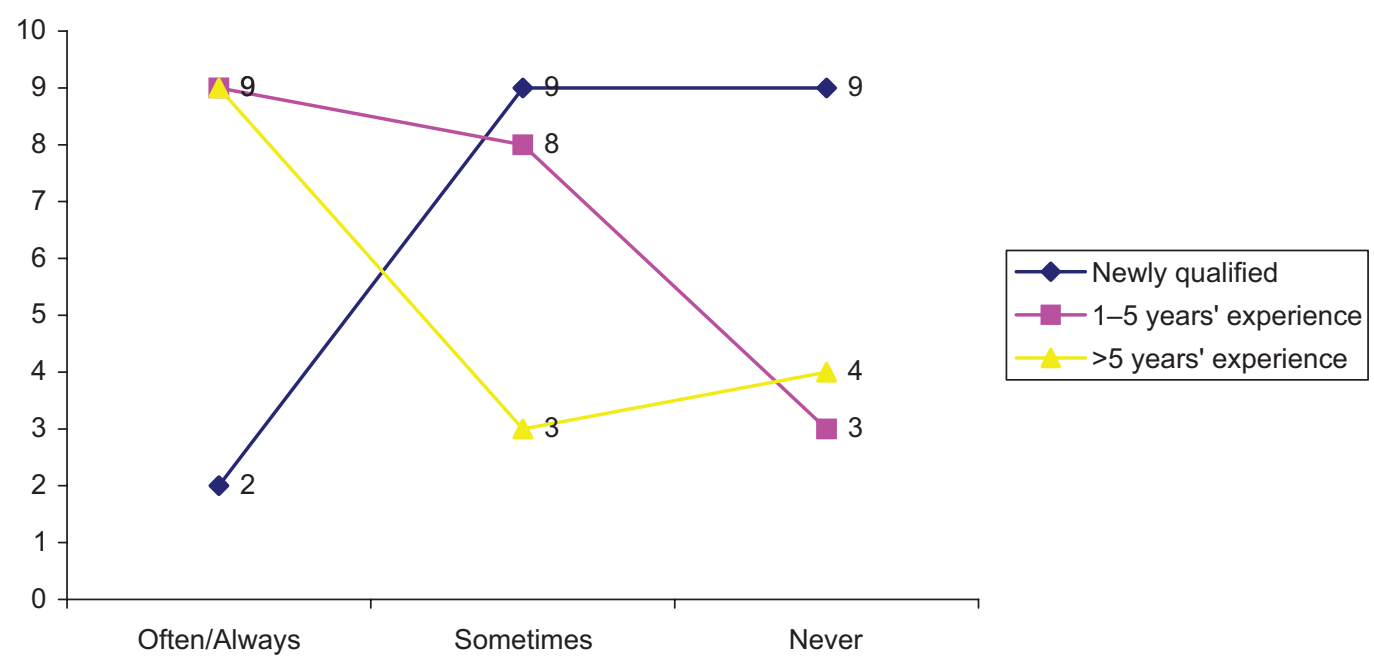

Figure 3 Responses to "How often do you estimate pulse and respiratory rate?" stratified according to clinical experience.

affected the way they took pulse and respiratory rates. ${ }^{a}$ Together, these results suggest that the policy is causing the majority of doctors to estimate pulse/respiratory rate instead of measuring.

As mentioned in the introduction, the conflict between the policy and measuring the pulse against a watch can be resolved by using a watch attached to other parts of the clothing. However, of doctors who did not wear wristwatches, only 19 (42\%) used this solution. And 14 of these $19(74 \%)$ nevertheless estimated (sometimes or always). Yet 12 of these 14 said that if it were available, they would use a watch rather than estimating. This implies that a watch attached to the clothing is often not considered "available".

\section{Conclusions}

This audit aroused considerable interest on the part of those responding to the questionnaires. Some strongly felt that the 'bare below the elbow' policy had affected their ability to measure pulse/respiratory rate, with a minority indeed deciding to flout the policy in favor of having a watch easily available. Conversely, others did not feel it important to have a watch, either because they were able to estimate accurately, or because they felt it was not important to have an accurate measurement (normal, fast or slow being

${ }^{a}$ This finding might possibly be flawed, as it is based on answers to the question "Do you feel that the 'bare below the elbow' policy has affected the way you take pulse/respiratory rate?" which did not specifically ask if the policy had affected practice adversely. This question should be rectified in future audits. However it is unlikely that this error had a significant effect on the findings, as it was reasonably clear from the context that the question intended to ask about adverse effect. adequate). Indeed, the results showed that more experienced doctors were more likely to estimate. However, several respondents commented that they did not understand how those who estimate could differentiate between a pulse rate of 90 and one of 110 , which would change clinical decision making.

The majority fell between these two extremes. They felt that if a watch was available they would use it, but due to the lack of an available watch they would instead estimate. The results therefore suggest that although the 'bare below the elbow' policy is widely adhered to, this adherence leads to more estimation of pulse and respiratory rate.

The compromise of wearing a watch attached to other parts of the clothing is not a perfect solution - many doctors do not attach a watch to their clothing, and even of those who do, many still estimate. It seems that a watch attached to clothing is more inconvenient to use than a wristwatch. (Some doctors even admitted to taking out their mobile phone to time the pulse, a practice that might appear unprofessional).

Furthermore, there is a wide range of practice amongst doctors when taking pulse and respiratory rate. Of course, like any clinical skill there are various correct ways of doing things. And the way pulse and respiratory rate are measured often depends on clinical context. For example, doctors may take care to measure accurately if the patient appears unwell, or if the pulse/respiratory rate is estimated to be abnormal. Other doctors estimate one parameter whilst measuring the other. (These practices bring to light flaws in the audit questionnaire, which could have been designed to accommodate these points of view). It must also be remembered that the exact pulse/respiratory rate can often be ascertained from 
electronic monitors or from bedside observation charts, which show trends too.

\section{Recommendation}

It would not be possible to compel doctors to use a watch when taking pulse and respiratory rate; as discussed above, it is not always necessary. However, it might be practical to introduce a requirement for doctors to attach a watch to their clothing (whether belt, stethoscope, or neck fob), so it is at least available when wanted; according to the results, this would reduce estimation and increase accurate measurement. It should be the responsibility of the hospitals who uphold the bare below the elbow policy to provide these watches.

To introduce this as policy would however depend upon two crucial points not addressed in this audit: (1) how accurately doctors are able to estimate, and (2) if patient care is actually affected by a lack of accuracy in taking pulse/ respiratory rate. These points would require further study.

\section{Acknowledgments}

Dr Robert Ghosh, Consultant Physician and Director of ICU at Homerton University Hospital supervised and advised the author on this audit. Acknowledgment is also made to the doctors who took part in the audit by responding to the questionnaire.

\section{Disclosure}

The author declares no conflicts of interest.

\section{References}

1. Douglas G, Nicol F, Robertson C, editors. Macleod's Clinical Examination. 11th ed. Edinburgh, UK: Elsevier Churchill Livingstone; 2005.

2. Swash M, Glynn M, editors. Hutchison's Clinical Methods. 22nd ed. Saunders Elsevier; 2007.

3. Cox NLT, Roper TA, editors. Clinical skills. Oxford, UK: Oxford University Press; 2005.

4. Thomas J, Monaghan T. Oxford Handbook of Clinical Examination and Practical Skills. Oxford, UK: Oxford University Press; 2007.

5. Department of Health [online]. c2007-2008. Available from: www. dh.gov.uk/en/News/Speeches/DH_080106. Accessed May 31, 2010.

6. Homerton.nhs.uk [online]. London: Homerton University Hospital NHS Foundation Trust; c2008. Available from www.homerton.nhs.uk/patientinformation/infection-prevention-and-control/\#h007. Accessed May 31, 2010.

7. BMA Board of Science. Tackling healthcare associated infections through effective policy action (2009). Available from: http://www.bma.org. uk/images/Tackling\%20healthcare $\% 20$ associated $\% 20$ infections $\% 20$ through\%20effective\%20policy\%20action_tcm41-188116.pdf. Accessed May 31, 2010.

8. Dancer SJ. Pants, policies and paranoia. J Hosp Infect. 2010;74(1): $10-15$.
Clinical Audit

\section{Publish your work in this journal}

Clinical Audit is an international, peer-reviewed, open access journal focusing on the processes and outcomes of clinical audit in any area of healthcare. All aspects of patient care are addressed within the journal and practitioners from all disciplines are invited to submit their work. Areas covered include: Publication of audits; How an audit has changed practice;

\section{Dovepress}

Practical tips on how to do audits and to avoid pitfalls; How audits have changed patient care; Calls and justifications for new audits. The manuscript management system is completely online and includes a very quick and fair peer-review system, which is all easy to use. Visit http://www.dovepress. com/testimonials.php to read real quotes from published authors. 